\title{
ANALISIS PRODUKTIVITAS TENAGA KERJA PADA PROYEK PEKERJAAN JEMBATAN AMASSANGAN
}

\author{
Jusmidah $^{1}$ \\ ${ }^{1}$ Dosen FT Universitas Andi Djemma Palopo \\ ${ }^{1}$ jusmidah_fidha@yahoo.co.id
}

\begin{abstract}
Abstrak
Penelitian ini dilakukan untuk menganalisis produktivitas tenaga kerja pada proyek pekerjaan jembatan amassangan, dalam dunia jasa konrtruksi, produktivitas tenaga kerja adalah salah satu faktor penentu keberhasilan sebuah proyek pembangunan. Mengukur tingkat produktivitas tenaga kerja ada berbagai macam cara, salah satunya yaitu dengan meneliti besarnya tingkat LUR (Labour Utilitation Rate) masing-masing pekerja, yaitu meneliti sampai seberapa tingkat efektivitas pekerja dalam bekerja. Besarnya tingkat produktivitas tenaga kerja dipengaruhi oleh banyak faktor, diantaranya adalah kondisi lapangan dan sarana bantu, keahlian pekerja, faktor umur atau usia pekerja, kesesuaian upah, pengalaman dalam bekerja, kesehatan pekerja, koordinasi dan perencanaan, jenis kontrak kerja, manajerial atau manajemen lapangan. Tujuan dari penelitian ini adalah untuk mengetahui tingkat produktivitas tenaga kerja. Penelitian ini dilakukan di proyek pekerjaan jembatan Amassangan. Penelitian dilakukan dengan cara mengamati tingkat produktivitas 10 tenaga kerja dan disertai pengisian kuesioner. Pengamatan tingkat produktivitas (LUR) dilakukan selama 3 hari pada masingmasing pekerja. Dari hasil pengumpulan data, baik data produktivitas dan kuesioner dilakukan proses pengolahan data dengan bantuan komputer program SPSS versi 15.
\end{abstract}

Kata Kunci : Produktivitas Tenaga Kerja, Proyek Pekerjaan Jembatan Amassangan, LUR, SPSS

\section{PENDAHULUAN}

Kota Palopo merupakan salah satu kota di Indonesia yang sedang berkembang. Dengan pertumbuhan itu,tentu juga akan berpengaruh terhadap banyaknya tenaga dalam proyek. Menurut UU No. 13 tahun 2003 Bab I pasal 1 ayat 2 disebutkan bahwa tenaga kerja adalah setiap orang yang mampu melakukan pekerjaan guna menghasilkan barang dan jasa baik untuk memenuhi kebutuhan sendiri maupun untuk masyarakat.

Proyek adalah suatu rangkaian kegiatan yang dikerjakan dalam waktu terbatas. menggunakan sumber daya tertentu dengan harapan untuk mempe roleh hasil yang terbaik pada waktu yang akan datang. Sumber daya merupakan factor penentu dalam keberhasilan suatu proyek kontruksi. Sumber daya yang berpengaruh dalam proyek terdiri dari man, materials, machine, money dan method.

Dalam upaya untuk mengatur atau memanajemen penggunaan sumber daya manusia agar realistis, maka kontraktor harus mengetahui tingkat produktivitas tenaga kerja. Hal tersebut sangat diperlukan untuk memantau dan memetakan apa yang akan terjadi pada sebuah proyek akibat penggunaan dan pemanfaatan tenaga kerja. Kurang diperhatikannya produktivitas tenaga kerja pada suatu proyek kontruksi dapat menghambat pekerjaan kontruksi itu sendiri. Produktivitas tenaga kerja yang baik sangat diperlukan untuk keberhasilan proyek kontruksi. Produktivitas tenaga kerja akan sangat berpengaruh juga terhadap besarnya keuntungan atau kerugian suatu proyek. Dalam pelaksanaan dilapangan hal tersebut terkadang bisa terjadi dikarenakan tenaga kerja yang kurang efektif didalam pekerjaannya. Contoh tindakan yang menyebabkan pekerjaan yang kurang effektif tersebut antara lain menganggur, ngobrol, makan, merokok, istirahat, yang kesemuanya itu dilaksanakan pada saat jam kerja. 
Dari latar belakang tersebut penulis akan melakukan penelitian tentang produktivitas tenaga kerja berdasarkan tingkat efektifitas dalam bekerja (labour utilization rate). Tujuan utama penelitian ini adalah untuk menganalisa tingkat produktivitas tenaga kerja pada suatu pekerjaan kontruksi dan menganalisa pengaruh variabel terhadap tingkat produktivitas tersebut.

Secara umum produktivitas diartikan sebagai hubungan antara hasil nyata maupun fisik dengan masukan sebenarnya. Misalnya saja, produktivitas adalah ukuran efisiensi produktif. Suatu perbandingan antara output dan input, masukan sering dibatasi dengan masukan tenaga kerja, sedangkan keluaran diukur dalam kesatuan fisik bentuk mental. Produktivitas juga diartikan sebagai tingkatan efisiensi dalam memproduksi barang atau jasa. L. Greenberg mendefinisikan produktivitas sebagai perbandingan antara totalitas pengeluaran pada waktu tertentu dibagi totalitas masukan selama periode tersebut.

Kelompok manajemen dalam organisasi bertugas pokok menggerakan orangorang lain untuk bekerja sedemikian rupa sehingga tujuan tercapai dengan baik. Halhal yang kita hadapi dalam manajemen, terutama dalam organisasi modern, ialah semakin cepatnya cara kerja sebagai pengaruh langsung dari kemajuan-kemajuan yang diperoleh dalam bidang ilmu pengetahuan dan teknologi yang mempengaruhi seluruh aspek organisasi seperti proses produksi, distribusi, pemasaran dan lain-lain. Kemajuan teknologi yang berjalan cepat harus diimbangi dengan proses yang terusmenerus melalui pengembangan sumber daya manusia, yakni melalui pendidikan dan pengembangan. Dari pendidikan, latihan dan pengembangan tersebut maka antara lain akan menghasilkan tenaga skill yang mengusai aspek-aspek teknis dan aspekaspek manajerial.

Hal-hal yang harus diperhatikan dalam kaitannya dengan faktor-faktor tenaga kerja ialah: (1) motivasi pengabdian, disiplin, etos kerja produktivitas dan masa depannya; (2) Hubungan industrial yang serasi dan harmonis dalam suasana keterbukaan (Muchdarsyah, 1992). Dengan mengetahui perkiraan angka dan jadwal kebutuhannya, maka dapat dimulai kegiatan pengumpulan informasi perihal sumber penyediaan,baik kualitas maupun kuantitas. Dalam pelaksanaan proyek, jumlah kebutuhan tenaga kerja yang terbesar adalah tenaga kerja lapangan. Tenaga kerja lapangan ini berhubungan langsung dengan pekerjaan fisik konstruksi di lapangan.

Dalam hubungan produktivitas dikenal pola umum yang menggambarkan profil kecenderungan naik turunnya produktivitas tenaga kerja (direct labor) selama tahap kontruksi yaitu mobilisasi, periode puncak dan periode menurun. Semua faktor yang mempengaruhi produktivitas dipandang sebagai sub system untuk menunjukkan dimana potensi produktivitas dan cadangannya disimpan. Menurut Kaming dalam Wulfram I Ervianto (2005) faktor yang mempengaruhi produktivitas proyek diklasifikasikan menjadi empat kategori utama, yaitu:

1) Metode dan teknologi, terdiri atas faktor: desain rekayasa, metode konstruksi, urutan kerja, pengukuran kerja.

2) Manajemen lapangan, terdiri atas faktor: perencanaan dan penjadwalan, tata letak lapangan, komunikasi lapangan, manajemen material, manajemen peralatan, manajemen tenaga kerja.

3) Lingkungan kerja, terdiri atas faktor: keselamatan kerja, lingkungan fisik, kualitas pengawasan, keamanan kerja, latihan kerja, partisipasi.

4) Faktor manusia, tingkat upah pekerja, kepuasan kerja, pembagian keuntungan, hubungan kerja mandor-pekerja. 
Menurut Iman Soeharto variabel-variabel yang mempengaruhi produktivitas tenaga kerja lapangan dapat dikelompokan menjadi: kondisi fisik lapangan dan sarana bantu, kepenyeliaan, perencanaan dan koordinasi, komposisi kelompok kerja, kerja lembur, ukuran besar proyek, pekerja langsung versus kontraktor, kurva pengalaman, dan kepadatan tenaga kerja.

Selama berlangsungnya pekerjaan harus diukur hasil-hasil yang dicapai untuk dibandingkan dengan rencana semula. Obyek pengawasan ditujukan pada pemenuhan persyaratan minimal segenap sumber daya yang dikerahkan agar proses kontruksi secara teknis dapat berlangsung baik. Upaya mengevaluasi hasil pekerjaan untuk mengetahui penyebab penyimpangan terhadap estimasi semula. Dalam penelitian ini pengamatan dilakukan dengan metode produtivity rating, dimana aktivitas pekerja diklasifikasikan dalam 3 hal yaitu Essential contributory work, Effective work (pekerjaan efektif), dan Not Useful (pekerjaan tidak efektif). Sehingga faktor utilitas pekerja (LUR) dapat dihitung :

Faktor utilitas pekerja $=\frac{\text { Waktu bekerja evektif }+1 / 4 \text { waktu bekerja konstribusi }}{\text { Pengamatan total }} \times 100 \%$

Pengamatan total $=$ waktu efektif + waktu kontribusi + waktu tidak efektif. Untuk sebuah tim kerja dikatakan mencapai waktu efektif atau memuaskan bila faktor utilitas pekerjanya lebih dari 50\% (Oglesby, 1989:180-181).

\section{METODOLOGI PENELITIAN}

Metode dalam penelitian ini adalah metode analisis deskriptif yaitu penelitian dengan mengumpulkan data primer dan data sekunder. Proses pencarian data dilakukan dengan cara observasi ke lapangan langsung, pengisian angket quisioner, wawancara, dan studi literatur. Dalam pengukuran produktivitas terdapat banyak metode yang bisa digunakan, salah satunya productivity rating, dimana aktivitas pekerja diklasifikasikan dalam 3 hal, yaitu Essential contributory work, Effective work, dan not useful. Sedangkan pengukuran dan pengolahan data variabel yang mempengaruhi produktivitas tenaga kerja digunakan metode-metode pendekatan dengan pengolahan data.

Penelitian ini mengambil lokasi pada proyek pembangunan struktur jembatan Amasangan,yang berlokasi di Jalan Jendral Sudirman ( Jensud ) Kota Palopo. Pelaksanaan penelitian produktivitas tenaga kerja pada pekerjaan struktur jembatan Amasangan dilakukan selama jam kerja, dengan waktu istirahat 1 jam. Pelaksanaan penelitian ini dilakukan selama 3 hari pengamatan terhadap masing-masing pekerja.

Tahap dan prosedur analisa dilakukan secara sistematis. Adapun tahap dan prosedur analisa yang akan dilakukan adalah sebagai berikut :

1) Tahap I, yaitu tahap persiapan. Langkah yang dilakukan yaitu merumuskan masalah analisa, tujuan penelitian, menentukan hipotesis dan menggali kepustakaan serta pembuatan Kuesioner yang akan ditanyakan dalam analisa agar dapat berjalan lancar.

2) Tahap II, disebut tahap mencari data lapangan dan pengumpulan data. Langkah yang dilakukan dalam tahap ini adalah : (1) Survei lapangan untuk melihat apakah proyek yang ada memenuhi syarat untuk dijadikan lokasi penelitian., (2) Menentukan zona yang akan diamati, (3) pengumpulan data efektifitas pekerjaan tenaga kerja pada pekerjaan struktur jembatan yaitu dengan menganalisis pekerjaan yang dilakukan didalam satu hari jam kerja. 
3) Tahap III, disebut tahap penelitian atau scoring data kuesioner dan rekapitulasi data masukan tingkat LUR (produktivitas). Langkah yang dilakukan dalam tahap ini adalah memberikan scoring terhadap jawaban responden dalam Kuesioner dan menganalisis kinerja atau sumber daya manusia pada pelaksanaan konstruksi jembatan dengan cara menganalisis data pekerjaan efektif dan pekerjaan kontribusi yang dihasilkan dengan waktu kerjanya sehingga didapatkan koefisien produktivitas dalam prosentase pelaksanaan. Adapun perhitungan faktor utilitas pekerja (LUR) dapat dihitung sebagai berikut:

Faktor utilitas pekerja $=\frac{\text { Waktu bekerja evektif }+1 / 4 \text { waktu bekerja konstribusi }}{\text { Pengamatan total }} \times 100 \%$

Dimana Pengamatan total $=$ waktu efektif + waktu kontribusi + waktu tidak efektif.

4) Tahap IV, yaitu tahap pembahasan hasil analisis. Langkah yang dilakukan adalah melakukan pembahasan dari hasil penelitian terhadap hubungan dan faktor-faktor yang mempengaruhi terhadap tingkat produktivitas untuk mendapatkan kesimpulan.

\section{HASIL DAN PEMBAHASAN}

Waktu total bekerja efektif,tidak efektif dan konstribusi dan nilai LUR (laboratorium Untilitation Rate)/ faktor utilitas pekerja hari ke-1,2,dan 3.

Tabel.1. Top manager terdiri dari 3 orang pada hari pertama

\begin{tabular}{|c|l|c|c|c|c|}
\hline No & Nama & $\begin{array}{c}\text { Total Waktu } \\
\text { Bekerja Efektif } \\
\text { (menit) }\end{array}$ & $\begin{array}{c}\text { Total Waktu } \\
\text { Bekerja tidak } \\
\text { Efektif (menit) }\end{array}$ & $\begin{array}{c}\text { Waktu Bekerja } \\
\text { Konstribusi } \\
\text { (menit) }\end{array}$ & LUR \\
\hline 1. & Orang pertama & 340 & 55 & 25 & $\%$ \\
2. & Orang kedua & 285 & 125 & 10 & $\%$ \\
3. & Orang ketiga & 310 & 90 & 20 & $\%$ \\
\hline
\end{tabular}

Tabel.2. Top manager terdiri dari 3 orang pada hari ke-2

\begin{tabular}{|c|l|c|c|c|c|}
\hline No & Nama & $\begin{array}{c}\text { Total Waktu } \\
\text { Bekerja Efektif } \\
\text { (menit) }\end{array}$ & $\begin{array}{c}\text { Total Waktu } \\
\text { Bekerja tidak } \\
\text { Efektif (menit) }\end{array}$ & $\begin{array}{c}\text { Total Waktu } \\
\text { Bekerja } \\
\text { Konstribusi } \\
\text { (menit) }\end{array}$ & LUR \\
\hline 1. & Orang pertama & 350 & 50 & 20 & $\%$ \\
2. & Orang kedua & 300 & 95 & 25 & $\%$ \\
3. & Orang ketiga & 290 & 110 & 20 & $\%$ \\
\hline
\end{tabular}

Tabel.3. Top manager terdiri dari 3 orang pada hari ke-2

\begin{tabular}{|l|c|c|c|c|}
\hline Nama & $\begin{array}{c}\text { Total Waktu } \\
\text { Bekerja Efektif } \\
\text { (menit) }\end{array}$ & $\begin{array}{c}\text { Total Waktu } \\
\text { Bekerja tidak } \\
\text { Efektif (menit) }\end{array}$ & $\begin{array}{c}\text { Total Waktu } \\
\text { Bekerja } \\
\text { Konstribusi } \\
\text { (menit) }\end{array}$ & LUR \\
\hline Orang pertama & 280 & 120 & 20 & $\%$ \\
Orang kedua & 295 & 95 & 30 & $\%$ \\
Orang ketiga & 320 & 95 & 5 & $\%$ \\
\hline
\end{tabular}

Tabel.4. Midle manager terdiri dari 3 orang pada hari pertama

\begin{tabular}{|c|c|c|c|c|c|}
\hline No & Nama & $\begin{array}{c}\text { Total Waktu } \\
\text { Bekerja Efektif } \\
\text { (menit) }\end{array}$ & $\begin{array}{c}\text { Total Waktu } \\
\text { Bekerja tidak } \\
\text { Efektif (menit) }\end{array}$ & $\begin{array}{c}\text { Total Waktu } \\
\text { Bekerja } \\
\text { Konstribusi }\end{array}$ & LUR \\
\hline
\end{tabular}




\begin{tabular}{|c|l|c|c|c|c|}
\hline & & & (menit) & \\
\hline 1. & Orang ke-empat & 265 & 135 & 20 & $\%$ \\
2. & Orang ke-lima & 300 & 100 & 20 & $\%$ \\
3. & Orang ke-enam & 285 & 120 & 15 & $\%$ \\
\hline
\end{tabular}

Tabel.5. Midle manager terdiri dari 3 orang pada hari ke-2

\begin{tabular}{|c|l|c|c|c|c|}
\hline No & Nama & $\begin{array}{c}\text { Total Waktu } \\
\text { Bekerja Efektif } \\
\text { (menit) }\end{array}$ & $\begin{array}{c}\text { Total Waktu } \\
\text { Bekerja tidak } \\
\text { Efektif (menit) }\end{array}$ & $\begin{array}{c}\text { Total Waktu } \\
\text { Bekerja } \\
\text { Konstribusi } \\
\text { (menit) }\end{array}$ & LUR \\
\hline 1. & Orang ke-empat & 290 & 100 & 30 & $\%$ \\
2. & Orang ke-lima & 300 & 100 & 20 & $\%$ \\
3. & Orang ke-enam & 345 & 50 & 25 & $\%$ \\
\hline
\end{tabular}

Tabel.6. Midle manager terdiri dari 3 orang pada hari ke-3

\begin{tabular}{|c|l|c|c|c|c|}
\hline No & Nama & $\begin{array}{c}\text { Total Waktu } \\
\text { Bekerja Efektif } \\
\text { (menit) }\end{array}$ & $\begin{array}{c}\text { Total Waktu } \\
\text { Bekerja tidak } \\
\text { Efektif (menit) }\end{array}$ & $\begin{array}{c}\text { Total Waktu } \\
\text { Bekerja } \\
\text { Konstribusi } \\
\text { (menit) }\end{array}$ & LUR \\
\hline 1. & Orang ke-empat & 305 & 100 & 15 & $\%$ \\
2. & Orang ke-lima & 285 & 120 & 15 & $\%$ \\
3. & Orang ke-enam & 340 & 70 & 10 & $\%$ \\
\hline
\end{tabular}

Tabel.7. Low manager terdiri dari 4 orang pada hari pertama

\begin{tabular}{|c|l|c|c|c|c|}
\hline No & Nama & $\begin{array}{c}\text { Total Waktu } \\
\text { Bekerja Efektif } \\
\text { (menit) }\end{array}$ & $\begin{array}{c}\text { Total Waktu } \\
\text { Bekerja tidak } \\
\text { Efektif (menit) }\end{array}$ & $\begin{array}{c}\text { Total Waktu } \\
\text { Bekerja } \\
\text { Konstribus } \\
\text { (menit) }\end{array}$ & LUR \\
\hline 1. & Orang ke-tujuh & 280 & 125 & 15 & $\%$ \\
2. & Orang ke-delapan & 260 & 130 & 30 & $\%$ \\
3. & Orang ke-sembilan & 330 & 80 & 10 & $\%$ \\
4. & Orang ke-sepuluh & 310 & 100 & 10 & $\%$ \\
\hline
\end{tabular}

Tabel.8. Low manager terdiri dari 4 orang pada hari ke-2

\begin{tabular}{|c|c|c|c|c|c|}
\hline \multicolumn{6}{|c|}{ HARI Ke-2 } \\
\hline No & Nama & $\begin{array}{l}\text { Total Waktu } \\
\text { Bekerja Efektif } \\
\quad \text { (menit) }\end{array}$ & $\begin{array}{c}\text { Total Waktu } \\
\text { Bekerja tidak } \\
\text { Efektif (menit) }\end{array}$ & $\begin{array}{l}\text { Total Waktu } \\
\text { Bekerja } \\
\text { Konstribusi } \\
\text { (menit) }\end{array}$ & LUR \\
\hline 1. & Orang ke-tujuh & 280 & 130 & 10 & $\%$ \\
\hline 2. & Orang ke-delapan & 310 & 95 & 15 & $\%$ \\
\hline 3. & Orang ke-sembilan & 310 & 90 & 20 & $\%$ \\
\hline 4. & Orang ke-sepuluh & 295 & 105 & 20 & $\%$ \\
\hline
\end{tabular}

Tabel.9. Low manager terdiri dari 4 orang pada hari ke-3

\begin{tabular}{|c|l|c|c|c|c|}
\hline \multicolumn{7}{|c|}{ HARI Ke-3 } \\
\hline No & Nama & $\begin{array}{c}\text { Total Waktu } \\
\text { Bekerja Efektif } \\
\text { (menit) }\end{array}$ & $\begin{array}{c}\text { Total Waktu } \\
\text { Bekerja tidak } \\
\text { Efektif (menit) }\end{array}$ & $\begin{array}{c}\text { Total Waktu } \\
\text { Bekerja } \\
\text { Konstribusi } \\
\text { (menit) }\end{array}$ & LUR \\
\hline 1. & Orang ke-tujuh & 300 & 100 & 20 & $\%$ \\
2. & Orang ke-delapan & 295 & 110 & 15 & $\%$ \\
3. & Orang ke-sembilan & 270 & 120 & 30 & $\%$ \\
4. & Orang ke-sepuluh & 280 & 120 & 20 & $\%$ \\
\hline
\end{tabular}


PENA TEKNIK: Jurnal Ilmiah Ilmu-Ilmu Teknik

Volume 1, Nomor 1, Maret 2016 : 47 - 54

Perhitungan Faktor Utilitas Pekerja

Tabel.10. Rekapitulasi Hasil Perhitungan LUR pada pekerjaan struktur jembatan Amassangan.

\begin{tabular}{|c|c|c|c|c|c|}
\hline No & Nama & $\begin{array}{c}\text { LUR } \\
\text { Hari } 1\end{array}$ & $\begin{array}{l}\text { LUR } \\
\text { Hari } 2\end{array}$ & $\begin{array}{l}\text { LUR } \\
\text { Hari } 3\end{array}$ & $\begin{array}{l}\text { Rata-Rata } \\
\text { LUR }\end{array}$ \\
\hline 1. & Orang Pertama & $82,44 \%$ & $84,52 \%$ & $67,86 \%$ & $78.27 \%$ \\
\hline 2. & Orang kedua & $68,45 \%$ & $72,92 \%$ & $72,02 \%$ & $70,99 \%$ \\
\hline 3. & Orang ketiga & $75,00 \%$ & $70,24 \%$ & $76,49 \%$ & $73,91 \%$ \\
\hline 4. & Orang keempat & $62,14 \%$ & $70,83 \%$ & $73,51 \%$ & $68,83 \%$ \\
\hline 5. & Orang kelima & $72,62 \%$ & $72,62 \%$ & $68,75 \%$ & $71,33 \%$ \\
\hline 6. & Orang keenam & $68,75 \%$ & $83,63 \%$ & $81,55 \%$ & $79,98 \%$ \\
\hline 7. & Orang ketujuh & $67,56 \%$ & $67,26 \%$ & $72,62 \%$ & $69,15 \%$ \\
\hline 8. & Orang kedelapan & $63,69 \%$ & $74,70 \%$ & $71,13 \%$ & $69,84 \%$ \\
\hline 9. & Orang kesembilan & $79,17 \%$ & $75,00 \%$ & $66,07 \%$ & $73,41 \%$ \\
\hline 10. & Orang kesepuluh & $74,40 \%$ & $71,43 \%$ & $67,86 \%$ & $71,23 \%$ \\
\hline & Rata-rata LUR & $64,58 \%$ & $74,32 \%$ & $71,79 \%$ & $72,69 \%$ \\
\hline
\end{tabular}

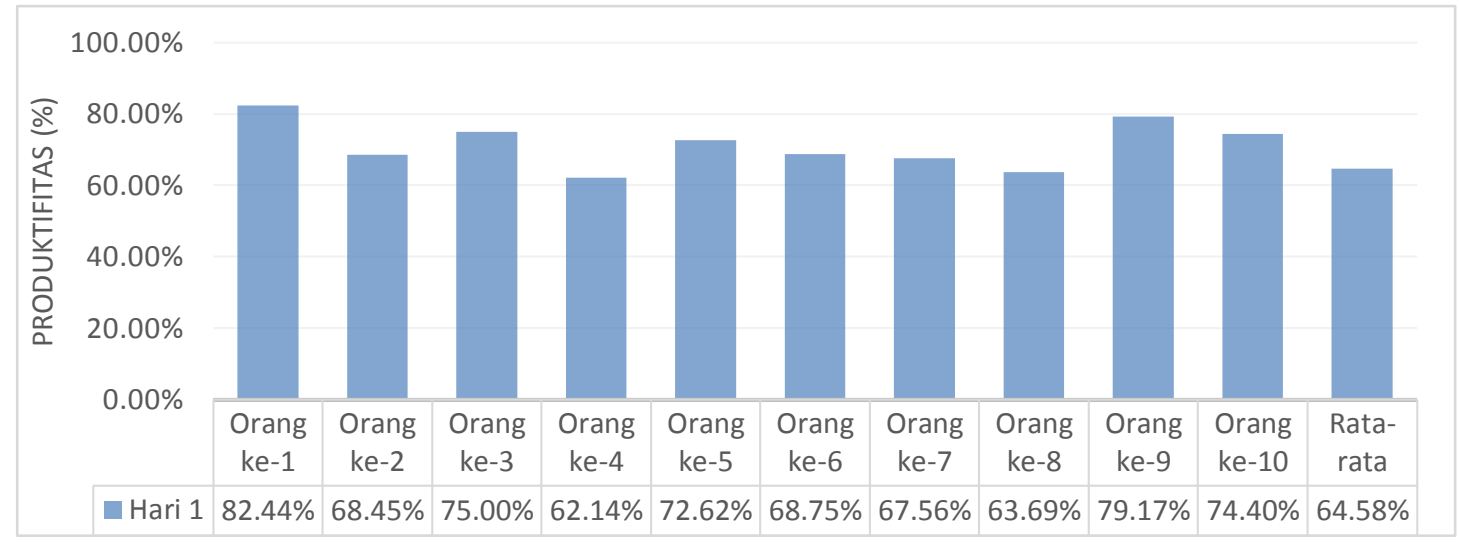

Gambar 1. Kurva hasil rekapitulasi produktivitas tenaga kerja pada hari pertama

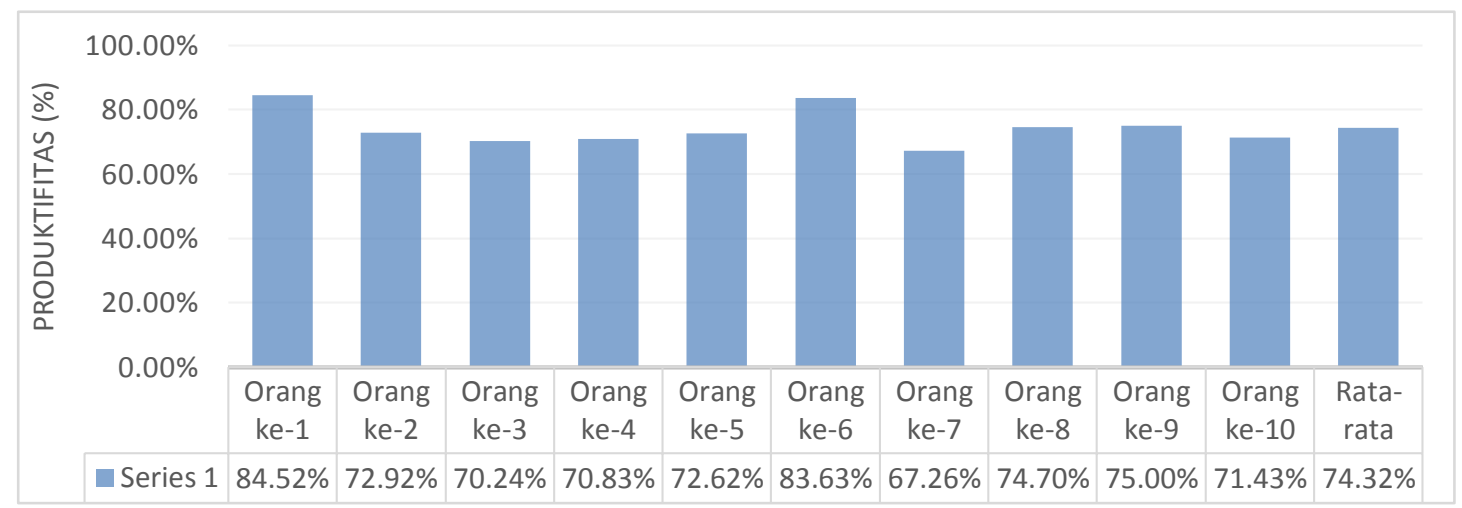

Gambar 2. Kurva hasil rekapitulasi produktivitas tenaga kerja pada hari kedua 


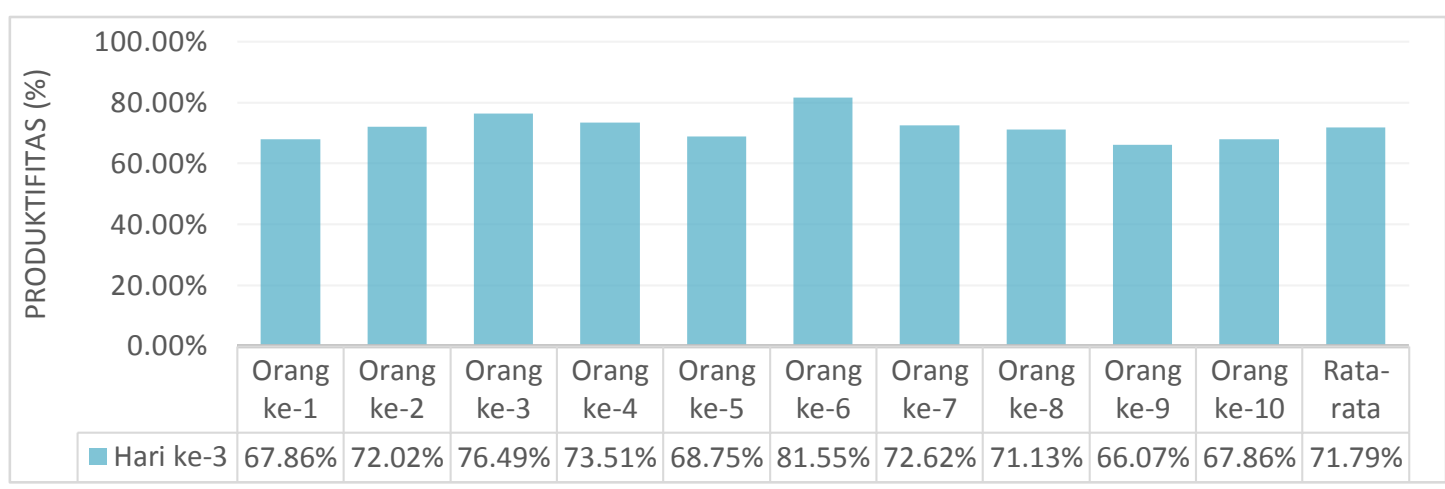

Gambar 3. Kurva hasil rekapitulasi produktivitas tenaga kerja pada hari ketiga

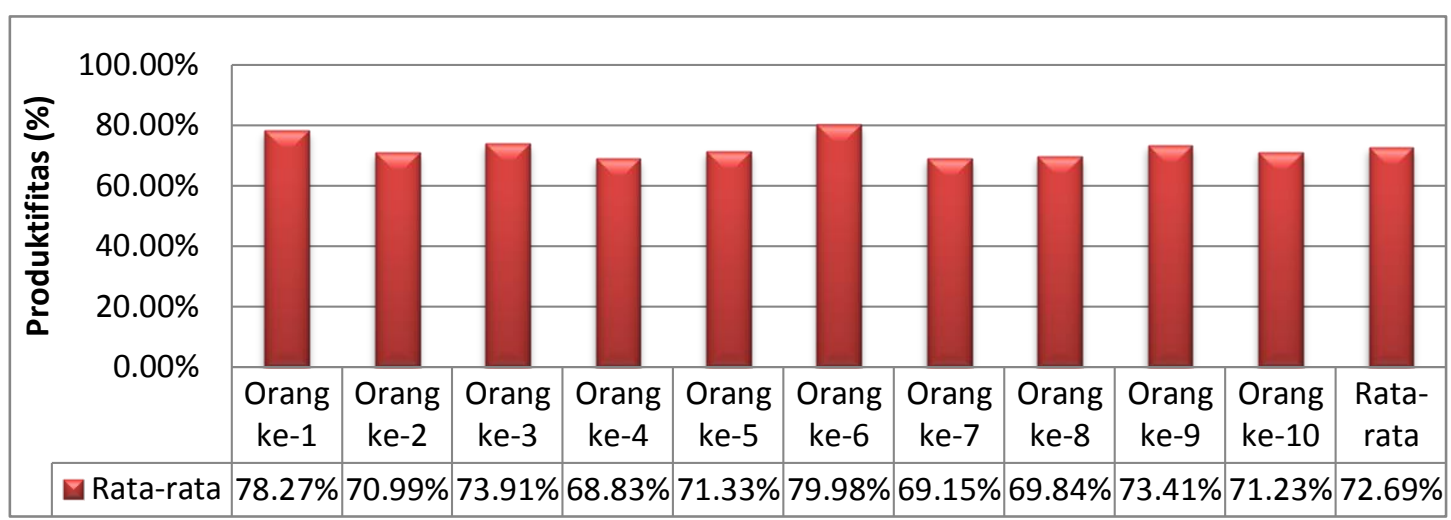

Gambar 4. Kurva rata-rata hasil keseluruhan produktivitas tenaga kerja

Dari hasil penelitian dapat diketahui faktor utilitas pekerja ( LUR ) yang paling besar pada hari pertama dilakukan oleh Orang pertama,yaitu sebesar 82,44\%. Dan hari kedua yaitu sebesar $84,52 \%$. Pada hari ketiga,faktor utilitas yang paling besar dilakukan oleh Orang ke-enam yaitu sebesar $81,55 \%$.Sedangkan rata-rata LUR dalam Tiga hari penelitian yang paling besar adalah ke-enam yaitu sebesar 79,98\%.Rata-rata tingkat LUR tertinggi terjadi pada hari ke-dua yaitu sebesar $74,32 \%$.Sedangkan rata-rata tingkat LUR Total yaitu sebesar 72,69\%.

Jadi dari data yang diperoleh dapat disimpulkan bahwa tingkat produktivitas pekerjaan pada pekerjaan struktur jembatan Amassangan cukup memuaskan,karena faktor utilitas pekerja atau nilai LUR (labour utilitation rate) lebih dari $50 \%$.

Tabel.11. Data jawaban kuesioner untuk semua variable yang mempengaruhi pekerjaan Struktur Jembatan

\begin{tabular}{|l|l|l|l|c|c|c|c|c|c|c|c|c|c|}
\hline No & Nama & \multicolumn{2}{|c|}{$\begin{array}{c}\text { Kedisiplin } \\
\text { an Waktu }\end{array}$} & \multicolumn{2}{c|}{$\begin{array}{c}\text { Pengalama } \\
\text { n Kerja }\end{array}$} & \multicolumn{2}{|c|}{ Usia } & \multicolumn{2}{c|}{$\begin{array}{c}\text { Keahlian } \\
\text { Pekerja }\end{array}$} & \multicolumn{2}{c|}{$\begin{array}{c}\text { Kesesuaian } \\
\text { Upah }\end{array}$} & \multicolumn{2}{c|}{$\begin{array}{c}\text { Kondisi } \\
\text { Lapangan }\end{array}$} \\
\hline & & A & B & A & B & A & B & A & B & A & B & A & B \\
\hline 1 & Orang ke-1 & X & & X & & X & & X & & & X & & X \\
\hline 2 & Orang ke-2 & X & & X & & X & & X & & X & & & X \\
\hline 3 & Orang ke-3 & X & & X & & & X & X & & & X & & X \\
\hline 4 & Orang ke-4 & X & & & X & & X & X & & & X & & X \\
\hline 5 & Orang ke-5 & X & & X & & & X & X & & X & & & X \\
\hline 6 & Orang ke-6 & X & & X & & X & & X & & X & & X & \\
\hline 7 & Orang ke-7 & X & & & X & X & & X & & X & & X & \\
\hline
\end{tabular}




\begin{tabular}{|l|l|l|l|l|l|l|l|l|l|l|l|l|l|}
\hline 8 & Orang ke-8 & X & & X & & X & & X & & & X & & X \\
\hline 9 & Orang ke-9 & X & & X & & X & & X & & X & & & X \\
\hline 10 & Orang ke-10 & X & & X & & X & & X & & & X & & X \\
\hline
\end{tabular}

Dari tabel di atas dapat disimpulkan, bahwa variabel kedisiplinan waktu jam kerja, dan Keahlian pekerja sangat berpengaru positif terhadap produktivitas pekerjaan struktur jembatan amassangan, karena diperoleh jawaban yang sama dari 10 tenaga kerja, sedangkan variabel yang lain diperoleh jawaban yang berbeda-beda, sehingga variabel tersebut tidak berpengaruh positif terhadap produktivitas pekerjaan jembatan tersebut.

\section{PENUTUP}

Dari analisis yang dilakukan,maka dapat diambil kesimpulan, besarnya tingkat produktivitas tenaga kerja pada pekerjaan proyek jembatan amassangan cukup memuaskan, karena faktor utilitas pekerja atau nilai LUR (labour utilitation rate) lebih dari 50\%, yaitu rata-rata sebesar 72,69 \%; variabel yang telah ditentukan yaitu, pengalaman kerja, usia, kesesuaian upah, dan kondisi lapangan, tidak mempunyai pengaruh yang signifikan terhadap besarnya produktivitas pekerjaan struktur jembatan amassangan; variabel kedisiplinan jam kerja, keahlian pekerja mempunyai pengaruh yang dominan terhadap tingkat produktivitas tenaga kerja diproyek jembatan Amassangan kota Palopo.

\section{DAFTAR PUSTAKA}

Anonim. 2005. Buku Pedoman Penulisan Tugas Akhir. Universitas Sebelas Maret Surakarta

Dipohusodo, Istimawan. 1995. Manajemen Proyek \& Kontruksi. Jilid 1. Yogyakarta : Badan. Penerbit Kanisius.

Dipohusodo, Istimawan. 1995. Manajemen Proyek \& Kontruksi. Jilid 2. Yogyakarta : Badan Penerbit Kanisius.

Nazir, Moh. 1983. Metode Penelitian. Jakarta : Ghalia Indonesia.

Oglesby. Dkk. 1989. Productivity Improvement in construction. McGraw-Hill Book Company : New York.

Prasetyo, Andi, 2004. Metode Tingkat Produktivitas Tenaga Kerja. Yogyakarta

Santoso, Singgih. 2006. Menguasai statistic di era informasi dengan SPSS 14. Jakarta : PT Elex Media Komputindo.

Sinungan, Muchdarsyah. 2003. Produktivitas Apa Dan bagaimana. Jakarta : Bumi Aksara.

Sodang P Sigian, 2002. Analisis Produktivitas dan Indikasi Variabel, edisi kedua. Yogyakarta.

Soeharto, Iman. 1989. Manajemen Proyek : Dari Konseptual Sampai Operasional. Jilid 1. Jakarta : Erlangga. 